Täuferei “. Es scheint mir durchaus angemessen, auf RassenMerkmale aufmerksam zu machen (wobei man sie allerdings auch als solche bezeichnen mufs); dann aber mufs man den Thieren auch Namen geben, sonst gehen die Notizen über sie im Laufe der Zeit verloren. Der Besitzer eines typischen Ex. kann, ohne die Frage studirt zu haben, oft gar keine genügende Auskunft über dasselbe geben, das kann der betreffende Fachmann viel besser. Für solchen ist nun Hr. Dohrn wohl kaum um deshalb zu halten, weil er von einer Streitfrage spricht, wenn er in seinen Ansichten von der des Hrn. Ganglbauer abweicht.

\title{
Ueber Cicindela octussis Dohrn, Stett. Zeit. 1885, p. 256.
}

So gern man zugeben wird, dafs "Cic. 10-punctata Mén. aus der Bucharei selbstständig ist", so unmöglich ist es, eine Cic. octussis Dohrn von ihr specifisch abzuzweigen, deren typisches Ex. (oder sind es mehrere?) von Merw stammt. Nach Hrn. Dohrn sollen die weifsen Flecke am Ende der Naht bei octussis gänzlich fehlen, sie fehlen aber auch bei einzelnen 10-punctata bereits fast gänzlich, bei einem Ex. aus Tecce-Turcmenien vollständig, ebenso bei einem Ex. aus Turcmenien, welches von Leder gesammelt, von Hrn. Reitter eingesendet wurde. Bei einem zweiten Stücke von Leder ist aber bereits deutlich ein weifser Querfleck vorhanden. Nach Hrn. Dohrn soll nun seine octussis die geringe Grölse mit campestris gemeinsam haben, während die mir vorliegenden octussis meine 4 Ex. der 10-punctata Mén. von Samarkand an Grölse übertreffen, auch sind die weifsen Flecke gröfser. Aufserdem soll die Oberseite von octussis "entschieden flachgedrückt" sein. Dafs dieser Umstand keine specifische Verschiedenheit begründet, so wenig wie die etwas geringere Grölse, leuchtet wohl jedem Unbefangenen ein!

Dagegen stimmen die drei mir vorliegenden Stücke aufser in der gröfseren Gestalt und den gröfseren weifsen Flecken darin überein, dafs sie einen schönen rothgoldenen Saum der Flügeldecken zeigen, der bei 10-punctata gar nicht hervortritt. Da nun Hr. Dohrn seine Var. octussis als besondere Art aufstellte, darf ich mir wohl erlauben, die schönen rothgold geränderten Ex. mit dem Namen var. auromarginata zu belegen.

Aehnlich wie bei Cic. campestris sind die Punkte des mittleren Fleckenpaars bei 10-punctata bisweilen mit einander verbunden; diese hübsche Var. nenne ich juncta.

Dr. G. Kraatz. 


\section{$2 \mathrm{BHL}$ Biodiversity Heritage Library}

Kraatz, G. 1887. "Ueber Cicindela octussis Dohrn, Stett. Zeit. 1885, p. 256." Deutsche entomologische Zeitschrift 1887(1), 150-150.

https://doi.org/10.1002/mmnd.48018870121.

View This Item Online: https://www.biodiversitylibrary.org/item/103946

DOI: https://doi.org/10.1002/mmnd.48018870121

Permalink: https://www.biodiversitylibrary.org/partpdf/235403

\section{Holding Institution}

Harvard University, Museum of Comparative Zoology, Ernst Mayr Library

\section{Sponsored by}

Harvard University, Museum of Comparative Zoology, Ernst Mayr Library

\section{Copyright \& Reuse}

Copyright Status: Public domain. The BHL considers that this work is no longer under copyright protection.

This document was created from content at the Biodiversity Heritage Library, the world's largest open access digital library for biodiversity literature and archives. Visit BHL at https://www.biodiversitylibrary.org. 